\title{
The influence of the albedo-temperature feed-back on climate sensitivity
}

\author{
Richard Bintanja and Johannes Oerlemans \\ Instituut voor Marien en Atmosferisch Onderzoek, Universiteit Utrecht, 3508 TA Utrecht, The Netherlands
}

\begin{abstract}
ABSTRAC'T. A vertically integrated, zonally averaged energy-balance climate model coupled to a two-dimensional ocean model with prescribed overturning pattern is employed to assess the seasonally and latitudinally varying response of the climate system to changes in radiative forcing. Since the sensitivity of the climate system depends on its actual state, considerable attention is given to the correct simulation of the important features of the present-day climate (such as surface air temperature, seaice and snow amount and meridional energy transport). The climate variability induced by the various elements of the albedo-temperature (e.g. sea-ice and snow) feed-back is quantified. It appears that the variability caused by sea-ice variations is approximately twice as large as for snow variations.
\end{abstract}

\section{INTRODUCTION}

Energy-balance climate models (EBCMs) have been used widely in the past to study the sensitivity of the climate system. Budyko (1969) and Sellers (1969a) independently developed simple EBCMs with which the latitudinally varying response to some change in radiative forcing was evaluated. Since then, the treatment of the physical mechanisms in EBCMs has improved considerably (e.g. distinction between land, atmosphere and ocean and between snow, sea ice and land ice, and inclusion of seasonal cycle).

In recent years, it has been shown that with similar types of seasonal EBCMs, the present-day climate can be reproduced to a reasonably good approximation (e.g. Peng and others, 1987; Harvey, 1988b), which is a prerequisite for a correct simulation of climate sensitivity. Therefore, considerable effort is put into the simulation of present-day climate. Since the model is highly simplified compared to the actual climate system, discussions on detailed structures are not very meaningful. Therefore, we will limit ourselves to the large-scale features and compare these with observations.

Here, it will be demonstrated that the seasonal and latitudinal response introduced by the albedo-temperature feed-back ( $\alpha-T$ feed-back, hereafter) in this EBCM is qualitatively similar to that of GCMs (e.g. Manabe and Stouffer, 1980). Three elements of the $\alpha-T$ feed-back will be distinguished: the dependence of sea-ice area, land snow area and snow/ice albedo on temperature. Only equilibrium results will be discussed in this paper.

\section{MODEL DESCRIPTION}

A zonally and vertically mean atmospheric layer is used, which is shown schematically in Figure 1. At the upper boundary, short-wave and long-wave radiative fluxes

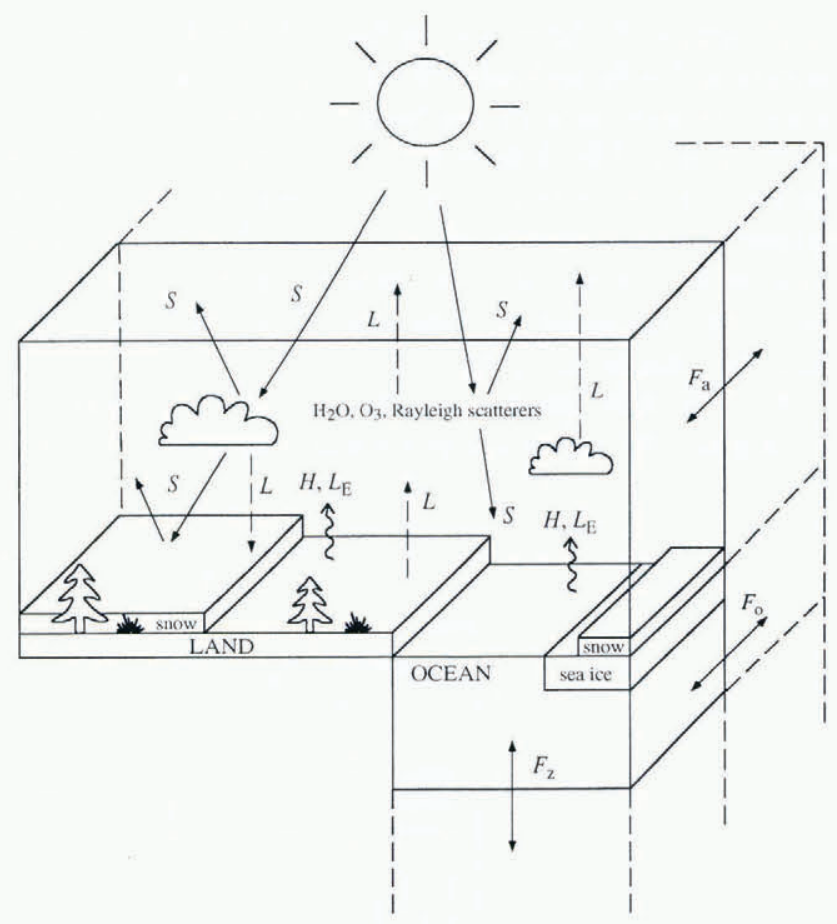

Fig. 1. Schematic illustration of a zonal band from the model, containing land, ocean, partial snow and sea-ice cover. $S$ and $L$ represent the short-wave and long-wave radiative fluxes, respectively. $H$ and $L_{\mathrm{E}}$ are the vertical turbulent fluxes of sensible and latent heat at the surface, respectively. $F_{\mathrm{a}}$ and $F_{\mathrm{o}}$ represent the total meridional heat fluxes in the atmosphere and ocean, respectively. $F_{z}$ is the vertical heat flux between the upper ocean layer and the deep ocean. 
must balance while at the lower boundary the atmosphere exchanges radiative and turbulent energy with land and ocean. The processes in the atmosphere (i.e. radiation, horizontal heat transport and turbulent exchange of energy) are expressed in terms of surface air temperature $\left(T_{\mathrm{a}}\right)$. The zonal mean surface air temperature is governed by the following equation:

$$
\begin{aligned}
\frac{\partial T_{\mathrm{a}}}{\partial t}= & \frac{1}{r^{2} \cos \varphi} \frac{\partial}{\partial \varphi} D_{\mathrm{a}} \cos \varphi \frac{\partial T_{\mathrm{a}}}{\partial \varphi} \\
& +\frac{\left(H+L_{E}+\Delta L_{\mathrm{a}}+\Delta S_{\mathrm{a}}\right)}{\left(c_{\mathrm{p}} \Delta p / g\right)}
\end{aligned}
$$

where $r$ is the Earth's radius, $\varphi$ is latitude, $D_{\mathrm{a}}$ is the diffusion coefficient for total atmospheric energy, $H$ and $L_{\mathrm{E}}$ are the surface-air fluxes of sensible and latent heat, respectively, $\Delta L_{\mathrm{a}}$ is the divergence of long-wave radiation, $\Delta S_{\mathrm{a}}$ is the absorbed short-wave radiation, and $c_{\mathrm{p}} \Delta p / g$ is the thermal inertia of the atmosphere.

In a model with a vertically averaged atmosphere, only the radiative fluxes at the top of the atmosphere (TOA) and at the surface need to be evaluated. Therefore, the evaluation of the vertical radiation distribution using sophisticated radiative transfer models is not necessary. A more convenient (and less timeconsuming) method is to use a radiative transfer model to parameterize the TOA and surface fluxes in terms of all important variables. The solar radiative transfer through the atmosphere is determined mainly by the amount of water vapour and ozone, solar zenith angle, cloud amount, cloud optical thickness and surface albedo. Using the 24 band model of Slingo and Schrecker (1982), the short-wave radiative fluxes are parameterized in terms of the quantities listed above. The long-wave fluxes are dependent on surface (air) temperature, water-vapour content, carbondioxide concentration, amount of ozone, cloud amount and cloud height. A broad-band emissivity radiative model is used to parameterize the long-wave fluxes in terms of the above-mentioned variables.

As in all EBCMs, the zonally averaged transport due to complicated, three-dimensional atmospheric motions is represented as a diffusive process in terms of the surface air temperature (first term on the righthand side of Equation (1)). According to Lorenz (1979) and Stone and Miller (1980), the diffusive treatment of the meridional transport is applicable when one considers long-term averaged radiative forcing while using a seasonal model. The diffusion coefficient $D_{\mathrm{a}}$ represents the diffusion coefficient for the total atmospheric flux, which meridional distribution is taken from Harvey (1988a).

With respect to zonal (land-ocean) energy transport, the "infinite wind" mixing case is adopted here (Peng and others, 1987). This means that one effective atmospheric layer overlies the land as well as the ocean part of a latitude band.

The turbulent fluxes of sensible and latent heat between the surface and the atmosphere are evaluated according to standard aerodynamic bulk relationships.

The land fraction at a specific latitude is subdivided into three surface types: grass, forest and permanent land ice. This distinction is applied to account for the differences in albedo between the types and to incorporate the effect of masking albedo changes due to snowfall in snow-covered forests Oerlemans and Van den Dool, 1978; Robock, 1980). The coverage of these land surface types is fixed at its present-day distribution which means that the latitudinal shift of vegetation zones under varying climatic conditions is neglected. The fractional amount of snow present on land $\left(a_{\mathrm{s}}\right)$, equally distributed over the three surface types, is expressed as a function of the surface air temperature (Harvey, 1988a):

$$
a_{\mathrm{s}}=\left\{\begin{array}{lr}
1 & T_{\mathrm{a}}^{\prime}<260 \mathrm{~K} \\
0.05\left(280-T_{\mathrm{a}}^{\prime}\right) & 260 \mathrm{~K} \leq T_{\mathrm{a}}^{\prime} \leq 280 \mathrm{~K} \\
0 & T_{\mathrm{a}}^{\prime}>280 \mathrm{~K}
\end{array}\right.
$$

where $T_{\mathrm{a}}^{\prime}=T_{\mathrm{a}}+\Gamma z$ is the surface air temperature corrected for the zonal mean surface elevation $(z)$ with a global mean lapse rate $\Gamma$ of $-6.5 \mathrm{~K} \mathrm{~km}^{-1}$. According to Robock (1980), the snow/ice albedo is a function of surface temperature, cloudiness and zenith angle.

The zonal mean ocean circulation is schematically illustrated in Figure 2. The velocity field $(u, w)$ is

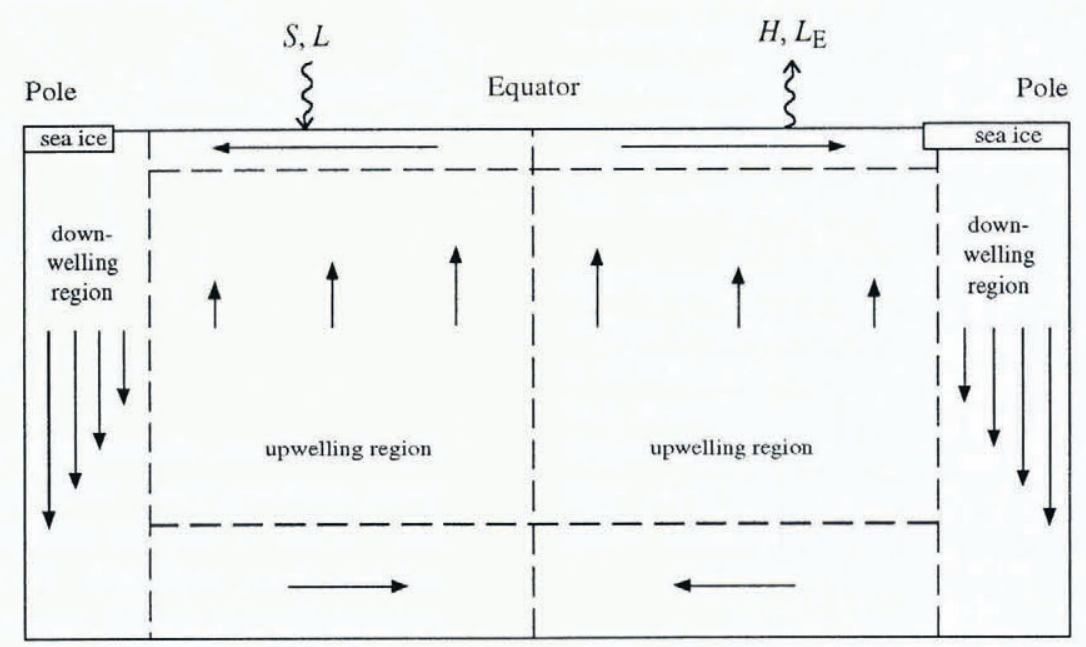

Fig. 2. Schematic illustration of the zonal mean thermohaline circulation in the ocean. The arrows indicate the direction of the flow. $S$ and $L$ represent the short-and long-wave radiative fluxes, respectively. $H$ and $L_{\mathrm{E}}$ represent the turbulent fluxes of sensible and latent heat between atmosphere and ocean. 
prescribed and kept fixed throughout the experiments. Upwelling takes place in the entire basin except for two areas at $50-70^{\circ} \mathrm{S}$ and $60-80^{\circ} \mathrm{N}$ where down-welling takes place; to complete the circulation, water flows poleward in the upper ocean layers and equatorward in the deep ocean. Thus, by transporting warm water poleward and cold water equatorward the thermohaline circulation effectively transports heat towards the poles. Further, a constant water depth of $4 \mathrm{~km}$ is assumed. The temperature equation for the ocean reads (Watts and Morantine, 1990):

$$
\begin{aligned}
\frac{\partial T_{\mathrm{o}}}{\partial t}+ & \frac{1}{f \cos \varphi} \frac{\partial\left(f \cos \varphi u T_{\mathrm{o}}\right)}{r \partial \varphi}+\frac{\partial\left(w T_{\mathrm{o}}\right)}{\partial z}= \\
& \frac{1}{r^{2} f \cos \varphi} \frac{\partial}{\partial \varphi}\left(D_{\mathrm{o}} f \cos \varphi \frac{\partial T_{\mathrm{o}}}{\partial \varphi}\right) \\
+ & \frac{1}{r^{2} f \cos \varphi} \frac{\partial}{\partial \varphi}\left(D_{\mathrm{h}} f \cos \varphi \frac{\partial T_{\mathrm{o}}}{\partial \varphi}\right) \\
+ & \frac{\partial}{\partial z}\left(D_{z} \frac{\partial T_{\mathrm{o}}}{\partial z}\right)+\frac{\left(\Delta L_{\mathrm{o}}+\Delta S_{\mathrm{o}}-H_{\mathrm{o}}-L_{\mathrm{E}_{\mathrm{o}}}\right)}{\rho_{\mathrm{w}} c_{\mathrm{w}} d_{\mathrm{m}}}
\end{aligned}
$$

in which $T_{0}$ is the ocean temperature, $z$ is the vertical coordinate, $f$ is the mean fractional basin width, $u$ and $u$ are the meridional and vertical velocity components, respectively, $D_{0}\left(=1.0 \times 10^{11} \mathrm{~m}^{2}\right.$ year ${ }^{-1}$ in the Southern Hemisphere and $4.0 \times 10^{11} \mathrm{~m}^{2}$ year $^{-1}$ in the Northern Hemisphere $)$ and $D_{\mathrm{h}}\left(=1.5 \times 10^{10} \mathrm{~m}^{2}\right.$ year $\left.^{-1}\right)$ are horizontal diffusion coefficients, $D_{z}=2.0 \times 10^{3} \mathrm{~m}^{2}$ year $^{-1}$ is the vertical diffusion coefficient, $\Delta L_{0}, \Delta S_{0}, H_{0}$ and $L_{\mathrm{E}_{0}}$ are the radiative and turbulent flux divergences in the upper ocean layer, and $\rho_{\mathrm{w}}, c_{\mathrm{w}}$ and $d_{\mathrm{m}}$ the density, specific heat capacity and thickness, respectively, of the uppermost ocean layer. The first term on the righthand side of Equation (3) represents the poleward heat transport by gyres and eddies in the uppermost ocean layer. In the interior of the basin, horizontal heat transport is represented by the second term on the righthand side with diffusion coefficient $D_{\mathrm{h}}$. The third term on the righthand side of Equation (3) represents all vertical mixing processes with diffusion coefficient $D_{z}$ (assumed to be constant with depth and latitude). The last term on the righthand side of Equation (3) is the amount of radiative and turbulent energy received by the uppermost ocean layer. As standard case, a mean upwelling velocity $w$ of $4 \mathrm{~m}^{\text {year }}{ }^{-1}$ is assumed (Hoffert and others, 1980), which implies overturning rates of 17.2 and 20.2 Sv in the Northern ( NH) and Southern Hemispheres (SH), respectively. However, the upwelling rate is assumed highest in the equatorial region and decreases linearly to zero at $50^{\circ} \mathrm{S}$ and $60^{\circ} \mathrm{N}$ (Fig. 2). Similarly, the down-welling velocities are assumed to increase linearly from zero to $70^{\circ} \mathrm{S}$ and $80^{\circ} \mathrm{N}$, respectively. The meridional distribution of the horizontal velocity $u$ then follows from the continuity equation

$$
\frac{1}{f \cos \varphi} \frac{\partial(f u \cos \varphi)}{r \partial \varphi}+\frac{\partial w}{\partial z}=0
$$

with the assumption of no advective heat fluxes through the lateral and vertical basin boundaries.

Sea ice is incorporated in a purely thermodynamic way. Only areal sea-ice variations are considered since they are considered to be much more important than variation in thickness with respect to the surface energy budget. The momentum exchange of sea ice with atmosphere or ocean is neglected, which means that drifting of sea ice is not included. When the water temperature of the upper ocean layer $\left(T_{\mathrm{W}}\right)$ becomes smaller than the freezing temperature of water $\left(T_{\mathrm{f}} \equiv 271.22 \mathrm{~K}\right.$ for a mean salinity of $35 \%$ ), sea ice with a specified thickness $\left(d_{\mathrm{i}}=2 \mathrm{~m}\right)$ starts to form. The fractional sea-ice cover $\left(a_{\mathrm{i}}\right)$ of a certain latitude band can be computed from conservation of energy

$$
c_{\mathrm{s}} \rho_{\mathrm{i}} d_{\mathrm{i}} \frac{\partial a_{\mathrm{i}}}{\partial t}=\rho_{\mathrm{w}} c_{\mathrm{w}} d_{\mathrm{w}} \frac{\partial \Delta \theta}{\partial t}
$$

in which $c_{\mathrm{s}}$ is the latent heat of melting $(=3.35 \times$ $\left.10^{5} \mathrm{~J} \mathrm{~kg}^{1}\right), \rho_{\mathrm{i}}$ the density of ice $\left(=920 \mathrm{~kg} \mathrm{~m}^{-3}\right), \rho_{\mathrm{w}}$ the density of sea water $\left(=1000 \mathrm{~kg} \mathrm{~m}^{-3}\right), c_{\mathrm{w}}$ the specific heat capacity of sea water $\left(=3.9 \times 10^{3} \mathrm{~J} \mathrm{~kg}^{-1} \mathrm{~K}^{-1}\right)$, and $\Delta \theta$ ( $=T_{\mathrm{f}}-T_{\mathrm{W}}$ ) the undercooling temperature. $\Delta \theta$ can become positive after the "new" temperature is evaluated.

After applying Equation (5), the water and sea-ice temperature are set equal to $T_{\mathrm{f}}$. If the fractional sea-ice amount becomes equal to 1.0 (i.e. the latitude band is entirely covered with sea ice), the sea-ice temperature $\left(T_{\mathrm{i}}\right)$ is allowed to decrease below $T_{\mathrm{f}}$ while the temperature of the underlying upper ocean layer remains equal to $T_{\mathrm{f}}$. The sea-ice variations are due mainly to variations of the energy balance at the ocean surface. The energy supplied to the uppermost ocean layer covered by sea ice through advection and diffusion in the ocean is implicitly equal to the energy flux through the base of the sea-ice layer and is therefore used to warm/cool the sea ice. Obviously, the melting process is rather similar to the freezing process described above.

The albedo of sea ice is taken similar to that of land ice with respect to its dependence on snow cover, zenith angle, surface temperature and cloudiness. The amount of snow covering the sea ice is governed by Equation (3) using sea-ice temperatures.

In the meridional direction, a $5^{\circ}$ grid distance is used in the ocean and atmosphere. The ocean is subdivided into six vertical layers with increasing layer thickness towards the bottom $(100,317,544,776,1012$ and $1251 \mathrm{~m}$ ). The meridional distribution of cloud amount is prescribed according to observations, while the globally uniform cloud optical depth is used to tune the model to its present-day state.

\section{SIMULATION OF PRESENT-DAY CLIMATE}

The characteristics of the differences between simulated and observed current-climate state will be discussed. The meridional distribution of the annual, zonal mean surface air temperature and its seasonal range are shown in Figure 3. The overall agreement seems to be good, although the model somewhat underestimates the surface air temperatures in the region $10-45^{\circ} \mathrm{N}$ (the maximum difference is about $4^{\circ} \mathrm{C}$ ). Temperatures over the Antarctic continent are significantly lower than over the North Polar basin (even when corrected to sea-level temperatures), as correctly simulated by the model. Due to the 


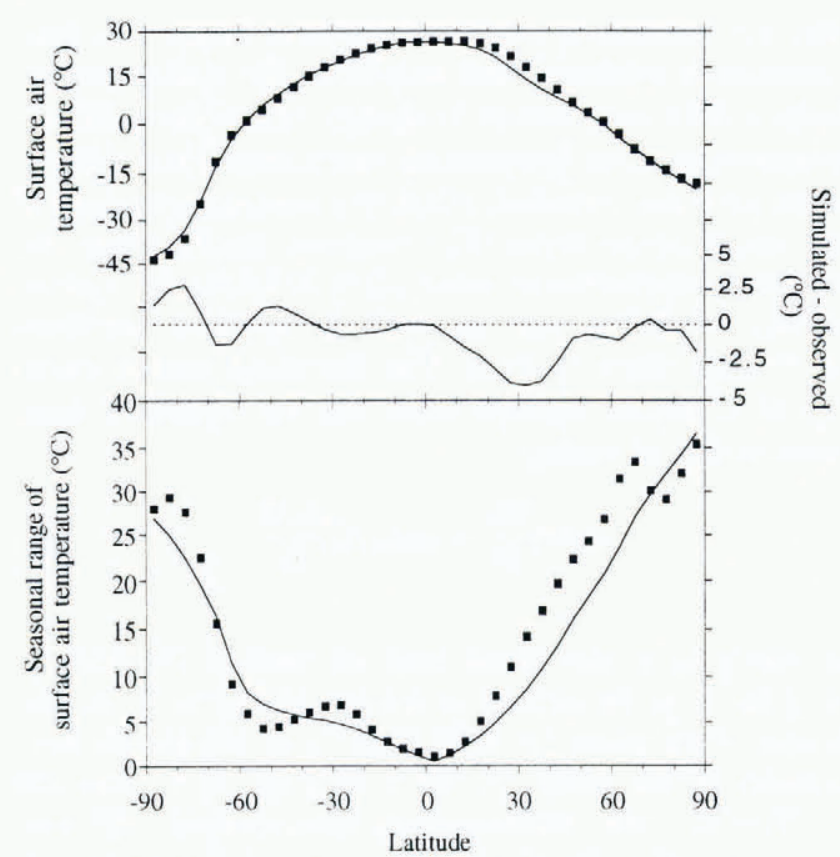

Fig. 3. Zonal and annual mean surface air temperature and its seasonal range (solid line). Dots are observations given by Warren and Schneider (1979).

large land masses in the $\mathrm{NH}$, the amplitude of the seasonal cycle of air temperature is largest there. The poleward enhancement of the seasonal temperature range, due to the poleward increase in seasonal amplitude of incident solar radiation, seems to be captured by the model, although the small-scale structures are not, possibly due to the use of "infinitewind" zonal atmospheric heat transport.

The model successfully reproduces the seasonally varying snow cover on land. On the other hand, some problems exist with respect to the seasonal behaviour of seaice amount: in the $\mathrm{NH}$, the seasonal range is overestimated while in the SH it is underestimated. The phase of the annual cycle seems to be simulated correctly, with extremes in sea-ice cover in February-March and August-September. The simulation of the latitudinal distribution of annual mean surface albedo seems fairly good as compared with values from Robock (1980), with maximum discrepancies of about 0.03 . Global mean values of the radiation budget are shown in Table 1 together with estimates from Sellers (1969b). The largest discrepancies seem to occur in the long-wave region. However, differences between the model and observations are relatively small and of the order of the accuracy of the observations.

Concerning the transport in the atmosphere, the model seems to be able to reproduce the main features, as indicated in Figure 4: maximum values of about $3 \times 10^{15} \mathrm{~W}$ at $45^{\circ}$ in both hemispheres. Obviously, these characteristics are imposed mainly by the choice of transport formulation and by the meridional distribution of the atmospheric diffusion coefficient $\left(D_{\mathrm{a}}\right)$. According to the (widely varying) observations, the maximum oceanic transport takes place at lower latitudes. This aspect is reproduced by the model due to the contribution of the meridional overturning (transport hereby is proportional to the meridional mass flux and temperature difference between top and bottom model ocean layer). Therefore,
Table 1. Observed (Sellers, 1969b) and model-generated mean annual, globally averaged radiative terms ( $\mathrm{Wm}^{-2}$ )

Observed

Model

\begin{tabular}{llrr}
\hline Net short-wave & Surface & 154 & 154.1 \\
& Atmosphere & 86 & 88.0 \\
& Total & 240 & 242.1 \\
Net long-wave & Surface & 55 & -50.7 \\
& Atmosphere & -185 & -190.7 \\
& Total & -240 & -241.4 \\
Net all-wave & Surface & 99 & 103.4 \\
& Atmosphere & -99 & -102.7 \\
& Total & 0 & 0.7
\end{tabular}

the inclusion of an overturning mechanism, simple as it may be, improves the meridional distribution of ocean heat transport compared to models which only take diffusive ocean transport into account. The eddy/gyre transport contributes little to the total oceanic transport, especially in
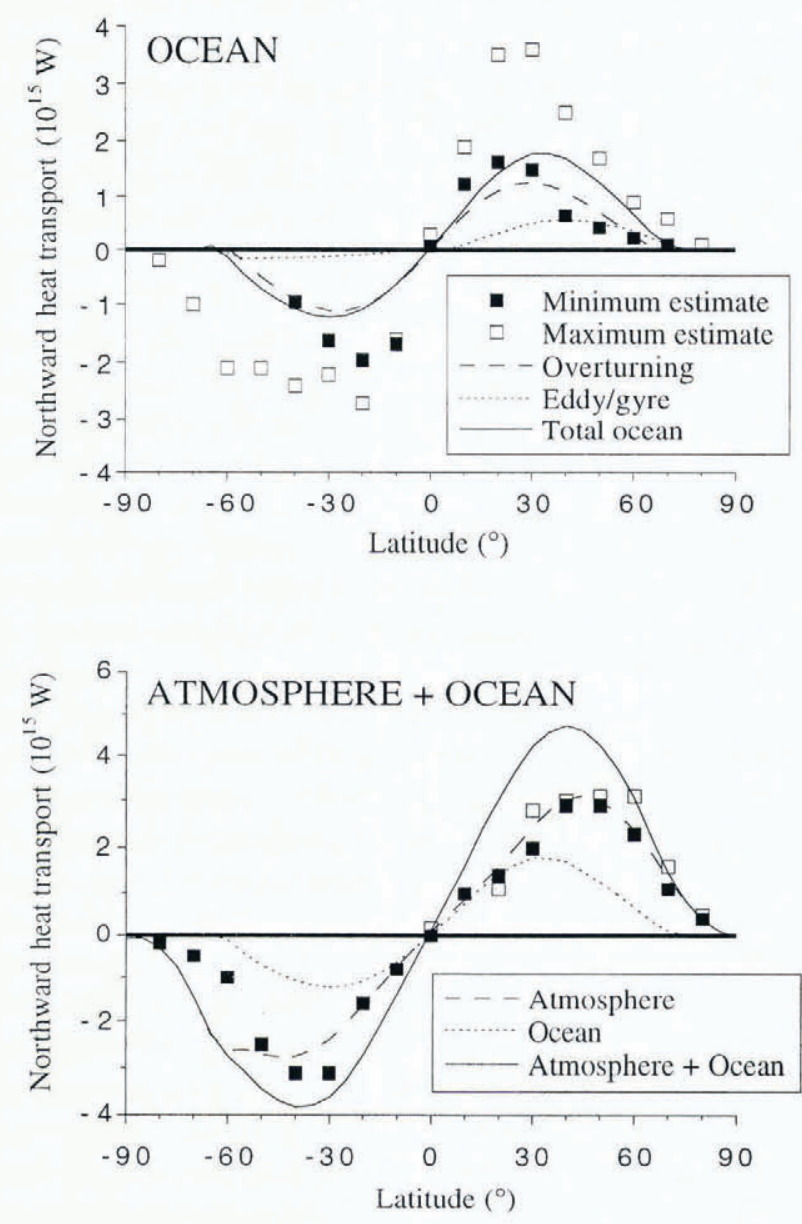

Fig. 4. Annual and zonal mean meridional energy transport in atmosphere and ocean. Minimum and maximum estimates of total ocean transport are from Hsuing (1985) and Carissimo and others (1985), respectively. In the lower panel, estimates of atmospheric transport are taken from Carissimo and others (black squares) and Oort and Vonder Haar (1976) (white squares). 
the $\mathrm{SH}$. This causes the total oceanic heat flux to be largest in the NH. However, the total ocean heat transport is still only half of the atmospheric transport.

\section{THE ALBEDO-TEMPERATURE FEED-BACK}

In order to quantify the contribution of each element of the $\alpha-T$ feed-back mechanism to the actual response, three separate effects are considered: (1) the dependence of sea-ice cover on temperature (referred to as sea-ice area feed-back, hereafter), (2) the dependence of snow cover on temperature (snow area feed-back), and (3) the dependence of snow/ice albedo on temperature snowalbedo feed-back). Four additional model versions have been constructed in which the element considered is fixed at its latitudinally and seasonally varying present-day distribution. The five models considered are:

A, Full $\alpha-T$ feed-back

$\mathrm{A}_{2}$ Sea-ice area fixed

$\mathrm{A}_{3}$ Land snow area fixed

$\mathrm{A}_{4}$ Snow/ice albedo fixed

$\mathrm{A}_{5}$ No $\alpha-T$ feed-back (i.e. $\mathrm{A}_{2}+\mathrm{A}_{3}+\mathrm{A}_{4}$ ).
A uniform decrease of $2 \%$ in solar insolation at TOA is applied. The latitudinal and seasonal distribution of change in surface air temperature for the five models is presented in Figure 5. The annual mean response for the various models is shown in Figure 6a. Obviously, the strong seasonal cycle in the response of model $\mathrm{A}_{1}$ in the polar regions is due entirely to variations in sea ice, since the response of model $\mathrm{A}_{2}$ shows no seasonal behaviour. All models including sea-ice variations $\left(A_{1}, A_{3}\right.$ and $\left.A_{4}\right)$ have this typical seasonal "sea-ice-induced" response, which can be characterized by a large seasonal variation in the response in surface air temperature of the polar regions. It is caused by enhanced heating of the ocean in summer as a result of reduced sea ice. The additional heat is released to the overlying atmosphere in winter, also due to reduced sea-ice cover (Manabe and Stouffer, 1980; Harvey, 1988b). If the sea-ice area is fixed (model $\mathrm{A}_{2}$ ), the polar amplification of sensitivity is virtually absent, similar to the response in the absence of the $\alpha-T$ feedback (model $\mathrm{A}_{5}$ ).

With sea ice fixed there is a slight increase in temperature change which peaks in the mid-latitudes between $30^{\circ}$ and $60^{\circ} \mathrm{N}$ (Fig. 6a). At these latitudes, where spring and autumn snow cover is still significant, net
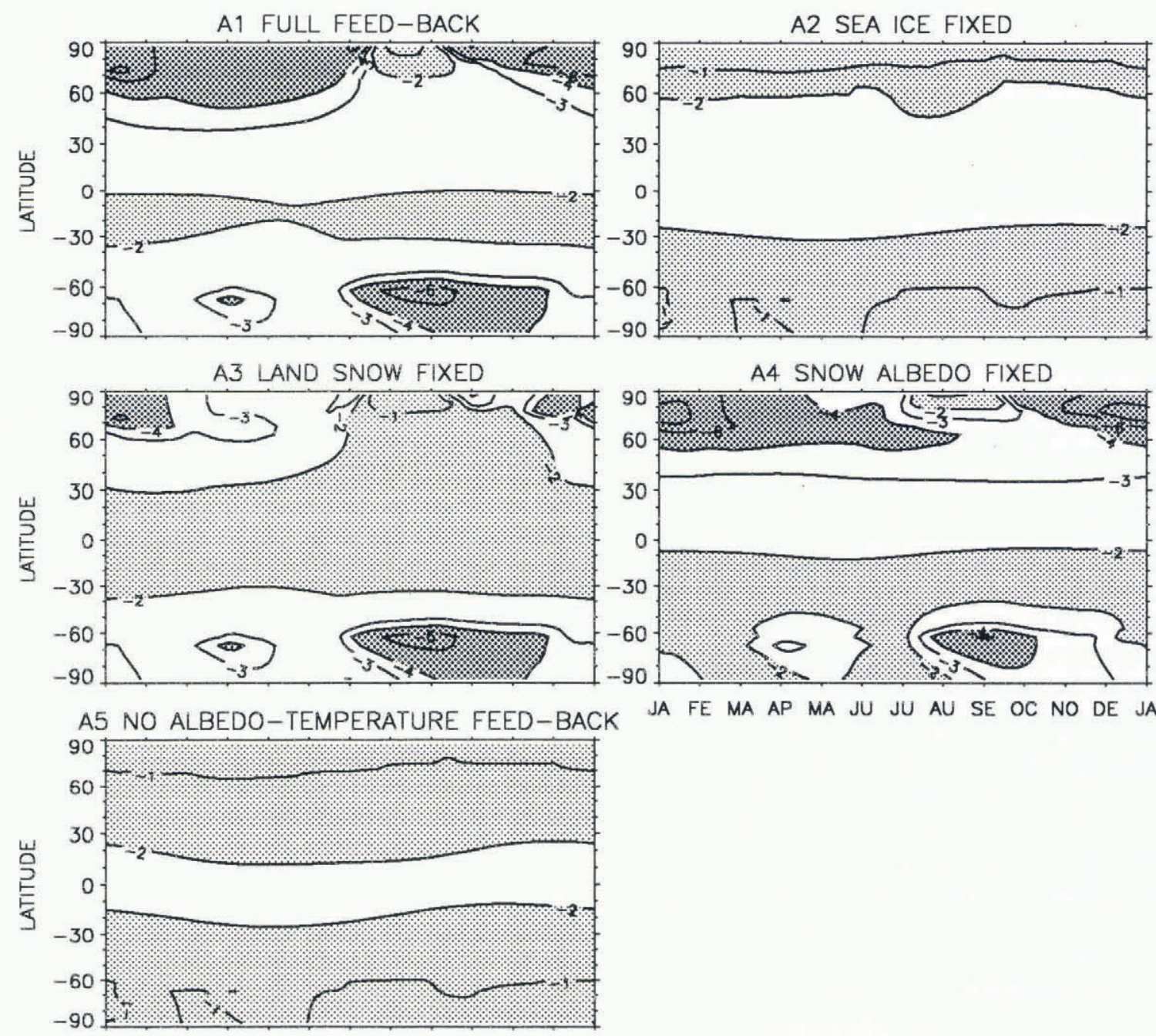

JA FE MA AP MA JU JU AU SE OC NO DE JA

JA FE MA AP MA JU JU AU SE OC NO DE JA

Fig. 5. Latitudinal and seasonal distribution of atmospheric lemperature change resulting from a $2 \%$ decrease in solar constant for models $A_{1}-A_{5}$. Light-grey and dark-grey areas represent lemperalure changes of less than $2^{\circ} \mathrm{C}$ and more than 4 C, respectively. 

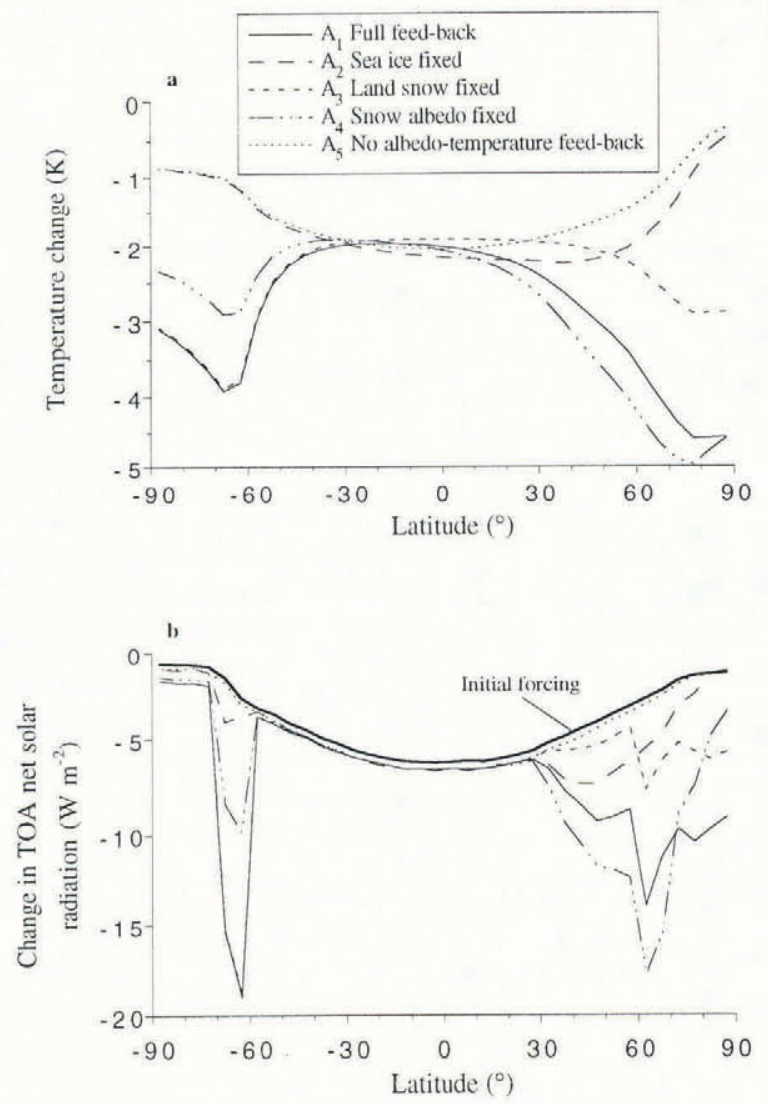

Fig. 6. Meridional distribution of the change in zonal and annual mean (a) surface air temperature and ( $b$ ) net solar radiation at TOA, resulting from a $2 \%$ decrease in solar constanl for models $A_{1}-A_{5}$. Also shown in (b) as "initial forcing" is the decrease in the TOA solar radiation just after the solar constant is reduced by $2 \%$ and without any climate feed-backs.

change in TOA solar radiation is largest, as can be inferred from Figure $6 \mathrm{~b}$. In the $\mathrm{SH}$, changes in solar radiation and temperature due to variations in snow cover are virtually absent since land snow cover outside the Antarctic continent does not exist in the present-day climate. The low sensitivity in the $\mathrm{NH}$ is due to the fact that, in the present-day state, snow cover is small in summer when changes in incident solar radiation are largest. As a result, the snow area feed-back is relatively weak compared to the sea-ice area feed-back. Although sensitivity induced by the snow area feed-back alone is small, it effectively enhances the sensitivity due to sea-ice area feedback in the $\mathrm{NH}$, as can be inferred from Figures 5 and 6 when the results of $A_{1}$ and $A_{3}$ are compared.

Unexpectedly, the omission of the dependence of the snow/ice temperature on albedo $\left(\operatorname{model} \mathrm{A}_{4}\right)$ enhances the sensitivity in the $\mathrm{NH}$, in contrast to the response in the $\mathrm{SH}$. Presumably, this is due to a sea-ice-induced shift in seasonal cycle of the surface temperature. However, since this is only a minor effect it will not be extensively discussed here.

In order to quantify the magnitude of these feed-back mechanisms, a linear feed-back analysis is adopted here. Generally, the change in global mean surface air temperature $(\Delta T)$ resulting from an initial change in TOA radiative forcing $(\Delta Q)$ can be written as:

$$
\Delta T=\lambda \Delta Q
$$

where $\lambda$ is referred to as the sensitivity parameter. In the absence of internal feed-backs, the sensitivity parameter $\left(\lambda_{0}\right)$ can be estimated from the derivative of the spectrally integrated Planck function at the effective radiation temperature $\left(T_{\mathrm{ep}}\right)$ :

$$
\lambda_{0}{ }^{-1}=\partial L / \partial T=4 \sigma T_{\mathrm{ep}}{ }^{3}
$$

which, for present-day value of $L$ (Table 1) gives $\lambda_{0}=$ $0.266\left(\mathrm{~W} \mathrm{~m}^{-2} \mathrm{~K}^{-1}\right)^{-1}$. With the inclusion of feed-back mechanisms, Equation (6) can be expressed as:

$$
\Delta T=\left(\lambda_{0}{ }^{-1}+\sum \lambda_{i}{ }^{-1}\right)^{-1} \Delta Q
$$

where subscript $i$ denotes feed-back mechanism $i$. It is generally assumed that the contributions to $\lambda^{-1}$ from the individual feed-back mechanisms combine linearly for small $\Delta Q$. Furthermore, it is assumed that the $\lambda_{i}^{-1}$ are independent of whatever other feed-back mechanism is present. Note, however, that the temperature response does depend on the presence of feed-back mechanisms, which implies that these can amplify each other with respect to the temperature response, as can be inferred from Equation (8). The values of $\lambda_{i}{ }^{-1}$ for each feed-back $i$ can be easily evaluated from the difference of the total $\lambda$ with and without feed-back $i$ operating. Thus, the $\lambda_{i}{ }^{-1}$ for each element of the $\alpha-T$ feed-back can be obtained from the global mean temperature response of models $\mathrm{A}_{1}-$ $\mathrm{A}_{5}$. The resulting values of $\lambda_{i}{ }^{-1}$ for a $2 \%$ decrease in solar constant $\left(S_{0}\right)$ are shown in Table 2. Note that $\lambda_{i}{ }^{-1}$ is negative for a positive feed-back.

The combined water-vapour-temperature feed-back for short-wave and long-wave radiation is larger than the total $\alpha-T$ feed-back, which amounts to $\lambda_{\alpha-T}{ }^{-1}=-0.77$ $\mathrm{W} \mathrm{m}{ }^{-2} \mathrm{~K}^{-1}$. It must be noted, however, that the sensitivity due to the water-vapour-temperature feed-back $\left(\lambda_{\mathrm{H}_{2} \mathrm{O}}{ }^{-1}\right)$ could not be evaluated independently. It was estimated as being the difference between the value of $\lambda$ produced by the "no $\alpha-T$ feed-back model" (model $\mathrm{A}_{5}$ ) and $\lambda_{0}$. Cess (1989) estimates $\lambda_{\mathrm{H}_{2} \mathrm{O}}{ }^{-1}=-1.2 \mathrm{~W} \mathrm{~m}^{-2} \mathrm{~K}^{-1}$ which agrees reasonably well with the value found here.

Table 2. Global mean values of the inverse sensitivity parameter associated with individual feed-back processes for a $2 \%$ decrease in solar constant

Process $\lambda_{\mathrm{i}}^{-1}$ $\mathrm{W} \mathrm{m}^{-2} \mathrm{~K}^{-1}$

$\partial L / \partial T$ 3.76

Water vapour

Snow area

Sea-ice area

$-0.53$

Snow albedo

0.04

Total 1.94 
As discussed above, global sensitivity due to sea-ice area feed-back is much larger than that due to snow area feed-back, whereas the snow/ice albedo feed-back is relatively weak. These results compare reasonably well with the values presented by Robock (1983). Using a seasonal EBCM he obtained for the snow area, sea-ice area and snow/ice albedo values of $\lambda_{i}{ }^{-1}$ of $-0.07,-0.45$ and $-0.13 \mathrm{~W} \mathrm{~m}^{2} \mathrm{~K}^{-1}$, respectively. Harvey (1988b) confirms our conclusion that the snow/ice albedo feedback has very little effect on global sensitivity. Cess and others (1991) compare snow area feed-back in 17 GCMs by perturbing the sea surface temperature for a perpetual April simulation. Without cloud feed-backs, the modelmean clear-sky inverse sensitivity parameter is about $-0.37 \mathrm{~W} \mathrm{~m}^{-2} \mathrm{~K}^{-1}$ with the extremes being -0.03 and -0.90 $\mathrm{W} \mathrm{m}^{-2} \mathrm{~K}^{-1}$.

Table 3 shows the inverse sensitivity parameter $\lambda_{\alpha-T}{ }^{-1}$ for the total $\alpha-T$ feed-back as determined in various modelling studies. Our model agrees roughly with three of the referred models. The two other models predict an $\alpha-T$ feed-back approximately only half as strong as in the other four models. This fact illustrates the need for more studies on the $\alpha-T$ feed-back. However, it may be safe to state that the total $\alpha-T$ feed-back is significantly weaker than the total water-vapourtemperature feed-back with respect to the global mean response for the present-day climate.

Table 3. The inverse sensitivity parameter for the total $\alpha-T$ feedback $\lambda_{\alpha-T^{-1}}\left(\mathrm{Wm}^{-2} \mathrm{~K}^{-1}\right)$ as delermined in various models for forcings of $2 \times \mathrm{CO}_{2}$ or $\mathrm{S}_{0} \pm 1-2 \%$. Adopted from Harvey (1988b)

\begin{tabular}{lll}
\hline Model & Reference & $\lambda_{\alpha-T}{ }^{-1}$ \\
\hline GISS GCM & Hansen and others (1984) & -0.35 \\
OSU GCM & Schlesinger (1985) & -0.7 \\
NCAR CCM & Dickinson and others (1987) & -0.7 \\
EBCM & Robock (1983) & -0.65 \\
EBCM & Harvey 1988b) & -0.32 \\
EBCM & This study & -0.77 \\
& &
\end{tabular}

For larger excursions off the current climate, the total global sensitivity shows a marked asymmetry, as shown in Figure 7. This is due mainly to a stronger $\alpha-T$ feed-back in colder climates, which is the main cause for $\lambda$ to increase as $S_{0}$ decreases. In colder climates, high reflective areas extend into regions with high insolation, which dramatically increases the change in TOA radiation balance resulting from a change in surface albedo. Therefore, the sensitivity of the model climate depends strongly on the state itself, which emphasises the importance of accurately simulating the present-day climate in studies concerning climate sensitivity.

\section{CONCLUSIONS}

In this paper, the albedo-temperature $(\alpha-T)$ feed-back is analyzed with a coupled EBCM ocean advection diffus-

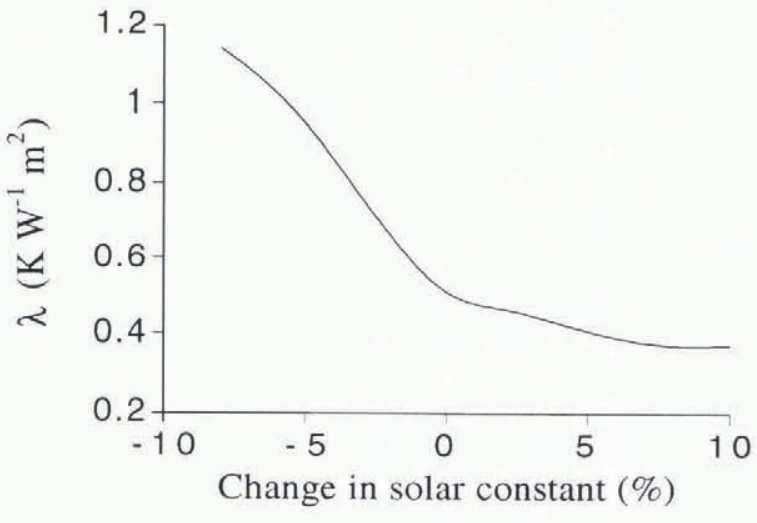

Fig. 7. Values of a sensitivity parameter $\lambda$ for a wide range of changes in solar constant.

ion model. In particular, its impact on the latitudinally and seasonally varying and global mean temperature response is discussed. The $\alpha-T$ feed-back is subdivided into three components, which are all dependent on temperature: (1) sea-ice area, (2) land snow-cover area, and (3) snow/ice albedo. The enhancement of the global sensitivity caused by the $\alpha-T$ feed-back is due mainly to sea-ice area feed-back. The snow area feed-back appears to be only half as strong as the sea-ice area feed-back while the snow/ice albedo feed-back is very small. Although the $\alpha-T$ feed-back introduces enhanced sensitivity of the polar regions, it is weaker than the water-vapour-temperature feed-back with respect to the global mean response. Comparison with other (types of) models shows that the global mean sensitivity produced by the $\alpha-T$ feed-back is probably well reproduced in the present model, although its interaction with other feedbacks not included in this model (e.g. cloud feed-backs) may significantly change these results.

\section{ACKNOWLEDGEMENTS}

J. de Wolde is acknowledged for his valuable comments on an earlier version of the manuscript. Financial support was provided by the Netherlands Antarctic Research Programme (GOA). This work was sponsored by the National Computing Facilities Foundation (NCF) for the use of supercomputing facilities, with financial support from the Netherlands Organisation for Scientific Research (NWO).

\section{REFERENGES}

Budyko, M. I. 1969. The effect of solar radiation variations on the climate of the Earth. Tellus, 21 5 , 61 I-619.

Carissimo, B. C., A. H. Oort and T. H. Vonder Haar. 1985. Estimating the meridional energy transports in the atmosphere and ocean. F. Phys. Oceanogr., 15, $82-91$.

Cess, R. D. 1989. Gauging water vapour feedback. Nature, 342, 736-737. Cess, R.D. and 32 others. 1991. Interpretation of snow-climate feedback as produced by 17 general circulation models, Science, 253 5022), $888-892$.

Dickinson, R. E., G. A. Meehl and W. M. Washington. 1987. Ice albedo feedback in a $\mathrm{CO}_{2}$-doubling scenario. Climatic Change, 10 (3), 241-248.

Hansen, J. and 7 others. 1984. Climate sensitivity: analysis of feedback mechanisms. Geophys. Monogr., Am. Geophys. Union 29, 130-163.

Harvey, L. D. D. 1988a. A semi-analytic energy balance climate model with explicit sea ice and snow physics. J. Climate, 1 11), 1065-1085. 
Harvey, L. D. D. 1988b. On the role of high latitude ice, snow, and vegetation feedbacks in the climatic response to external forcing changes. Climatic Change, 13 2), 191-224.

Hoffert, M. I., A.J. Callegari and C. -T. Hsieh. 1980. The role of deep sea heat storage in the secular response to climate forcing. J. Geophys. Res., 85 (11), 6667-6679.

Hsuing, J. 1985. Estimates of global oceanic meridional heat transport. J. Phys. Oceanogr., 15, 1405-1413.

Lorenz, E. N. 1979. Forced and free variations of weather and climate. 7. Atmos. Sci., 36, 1367-1376.

Manabe, S. and R.J. Stouffer. 1980. Sensitivity of a global climate model to an increase of $\mathrm{CO}_{2}$ concentration in the atmosphere. 7 . Geophys. Res., 85 C10), $5529-5554$.

Ocrlemans. J. and H. M. van den Dool. 1978. Energy balance climate models: stability experiments with a refined albedo and updated coeflicients for infrared emission. 7. Atmos. Sci., 35, 371-381.

Oort, A.H. and T.H. Vonder Haar. 1976. On the observed annual cycle in the ocean-atmosphere heat balance over the Northern Hemisphere. 7. Phys. Oceanogr., 6, 781-800.

Peng, L., M. -D. Chou and A. Arking. 1987. Climate warming due to increasing atmospheric $\mathrm{CO}_{2}$ : simulations with a multilayer coupled atmosphere-ocean scasonal energy balance model. J. Geophys. Res., 92 (D5), 5505-5521.
Robock, A. 1980. The seasonal cycle of snow cover, sea ice and surface albedo. Mon. Weather Rev., 108(3), 267-285.

Robock, A. 1983. Ice and snow feedbacks and the latitudinal and seasonal distribution of climate sensitivity. J. Atmos. Sci., 40 4), 986-997.

Schlesinger, M.E. 1985. Analyses of results from energy balance and radiative-convective models, In MacCracken, M.C. and F.M. Luther, eds. Projecting the climatic effects of increasing carbon dioxide. Washington, DC, U.S. Department of Energy, 81-147. (Report DOE/ER-0237.

Sellers, W. D. 1969a. A global climatic model on the energy balance of the Earth-atmosphere system. .7. Appl. Meteorol., 8, 392400.

Sellers, W. D. 1969b. Physical climatology. Chicago, etc., University of Chicago Press.

Slingo, A. and H. M. Schrecker. 1982. On the shortwave radiative properties of stratiform water clouds. Q. J. R. Meteorol. Soc., 108, 407-426.

Stone, P.H. and D.A. Miller. 1980. Empirical relations between seasonal changes in meridional temperature gradients and meridional fluxes of heat. J. Atmos. Sci., 37, 1708-1721.

Warren, S. G. and S. H. Schneider. 1979. Seasonal simulations as a test for uncertainties in the parameterizations of a Budyko-Sellers zonal climate model. J. Atmos. Sci., 36, 1377-1391.

Watts, R. G. and M. Morantine. 1990. Rapid climatic change and the deep ocean. Climate Change, 16, 83-97. 